\title{
Sporadic $E$ signatures revealed from multi-satellite radio occultation measurements
}

\author{
C. Arras ${ }^{1}$, C. Jacobi ${ }^{2}$, J. Wickert ${ }^{1}$, S. Heise ${ }^{1}$, and T. Schmidt ${ }^{1}$ \\ ${ }^{1}$ Helmholtz Center Potsdam, German Research Center for Geosciences GFZ, Department 1.1: GPS/Galileo Earth \\ Observation, Potsdam, Germany \\ ${ }^{2}$ University of Leipzig, Institute for Meteorology, Leipzig, Germany
}

\begin{abstract}
Radio occultation measurements performed by the satellites CHAMP, GRACE and FORMOSAT-3/COSMIC provide a huge data set for atmospheric and ionospheric investigations on a global scale. The data sets are used to extract information on sporadic $E$ layers appearing in the lower ionospheric $E$ region. This is done by analyzing signal amplitude variations of the GPS $L_{1}$ signal. Sporadic $E$ altitudes in northern midlatitudes found from radio occultation measurements are compared with ground-based ionosonde soundings. A large correlation of sporadic $E$ altitudes from these two techniques is found.
\end{abstract}

\section{Introduction}

The radio occultation (RO) technique enables space based observations of Earth's atmosphere on a global scale. The method has been established in the last years. The technique relies on accurate measurements of dual frequency phase delays by a low-Earth orbiting (LEO) satellite. The LEO tracks GPS (Global Positioning System) satellite signals, emitted with frequencies of $f_{L 1}=1575.42 \mathrm{MHz}$ and $f_{L 2}=1227.60 \mathrm{MHz}$, rising or setting behind the Earth's limb. The occultation geometry is illustrated in Fig. 1. Thereby, the GPS signals are received by a LEO satellite after travelling through the atmosphere, consequently containing information on atmospheric parameters like temperature, pressure and water vapour content in the lower neutral atmosphere (Rocken et al., 1997) and on electron density in ionospheric altitudes (Hajj and Romans, 1998). The retrieval is described in detail by, e.g., Kursinski et al. (1997).

One single occultation takes about 5 min while the atmosphere is scanned starting at LEO orbit altitude down to the

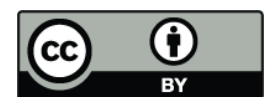

Correspondence to: C. Arras (arras@gfz-potsdam.de)

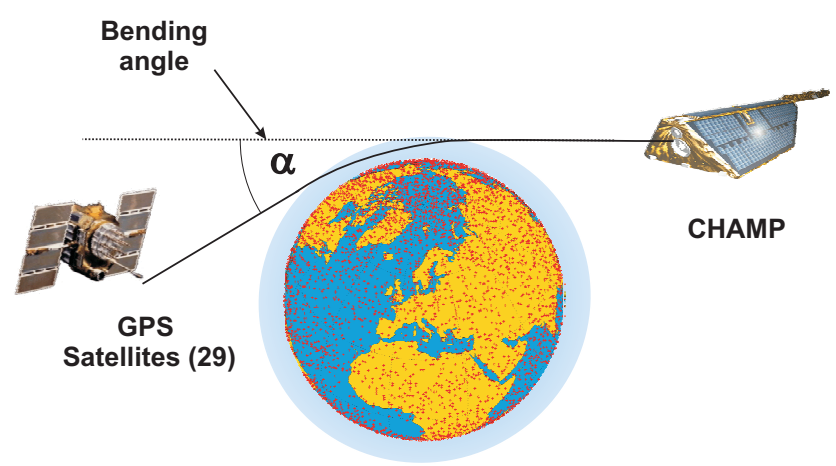

Fig. 1. Schematic representation of the occultation geometry. RO signals are transmitted by GPS satellites. The signals are received directly by a LEO (here CHAMP) satellite after passing Earth's atmosphere.

surface initially with $1 \mathrm{~Hz}$ sampling rate. Further down the sampling rate is switched to $50 \mathrm{~Hz}$ which refers to a height resolution of approximately $50 \mathrm{~m}$. The distribution of the upper boundary of the $50 \mathrm{~Hz}$ data is shown in Fig. 2. This plot refers to RO measurements performed during January 2007. Each of the three characteristic curves correspond to one of the three satellite missions that are introduced in the following section. Remarkable here is that the upper boundary of the $50 \mathrm{~Hz}$ profiles is usually located above $120 \mathrm{~km}$ altitude with slight differences between the different missions. The uppermost value of every single profile is sorted into $1 \mathrm{~km}$ height bins. To get a normalised altitude distribution the sum of every bin is divided by the total number of profiles recorded by the respective satellite mission.

Since the upper boundary is located above $120 \mathrm{~km}$ in most cases, the profiles allow for investigations of the lower ionospheric $E$ region. GPS waves are also sensitive to vertical electron density gradients, so that variations in the vertical profiles can directly be related to enhanced electron densities

Published by Copernicus Publications on behalf of the URSI Landesausschuss in der Bundesrepublik Deutschland e.V. 
Table 1. Overview on satellite characteristics of the CHAMP, GRACE and FORMOSAT-3/COSMIC missions.

\begin{tabular}{llll}
\hline Mission & CHAMP & GRACE & COSMIC \\
\hline Number of spacecrafts & 1 & & \\
\hline Leadership & GFZ & NASA/DLR & UCAR/NSPO \\
& Germany & USA/Germany & USA/Taiwan \\
\hline Launch & 15 July 2000 & 17 March 2002 & 15 April 2006 \\
\hline Expected lifetime & $2000-2010$ & $2002-2015$ & $2006-2011$ \\
\hline Science application & gravity field & gravity field & atmospheric sounding \\
& magnetic field & atmospheric sounding & ionospheric investigations \\
& atmospheric sounding & & \\
\hline Uppermost orbit altitude & $454 \mathrm{~km}$ & $500 \mathrm{~km}$ & $800 \mathrm{~km}$ \\
\hline Inclination & $87.3^{\circ}$ & $89^{\circ}$ & $72^{\circ}$ \\
\hline Dimensions & trapezoidal & trapezoidal & cylindrical \\
width & $1.6 \mathrm{~m}$ & $1.92 \mathrm{~m}$ & $0.16 \mathrm{~m}$ (of cylinder) \\
height & $0.75 \mathrm{~m}$ & $0.72 \mathrm{~m}$ & \\
length & $8.33 \mathrm{~m}$ incl. $4.04 \mathrm{~m}$ boom & $3.123 \mathrm{~m}$ & $70 \mathrm{~kg}$ per satellite \\
\hline Weight & $525 \mathrm{~kg}$ & $487 \mathrm{~kg}$ per satellite & \\
\hline
\end{tabular}

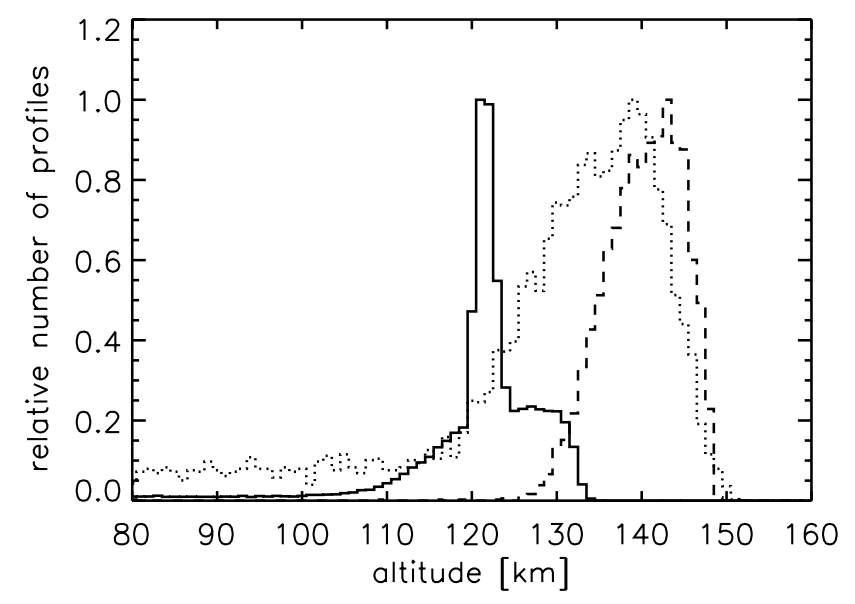

Fig. 2. Distribution of upper boundary of $50 \mathrm{~Hz}$ GPS RO measurements performed by CHAMP (dotted), GRACE (dashed) and FORMOSAT-3/COSMIC (solid) during January 2007.

here. Typical phenomena appearing in the altitude range between 90 and $120 \mathrm{~km}$ are so-called sporadic $E\left(E_{S}\right)$ layers. They can be considered as clouds of enhanced electron density with a thickness of usually $0.5-5 \mathrm{~km}$ and a horizontal extent of $10-1000 \mathrm{~km}$ (Wu et al., 2005). Sporadic E layers occur preferably in the midlatitudes of the summer hemi- sphere. They can reach an electron peak density of more the $10^{12} \mathrm{~m}^{-3}$ and may therefore disturb the global radio communication and navigation distinctly.

This paper intends to give an overview on the multisatellite radio occultation high-rate data base which can be used to monitor, beside neutral atmospheric behavior, also lower ionospheric characteristics. The global distribution of RO measurements is shown in the following sections. Additionally, it is described how to extract sporadic $E$ information from RO data. The resulting sporadic $E$ altitudes are finally compared with established ground based ionosonde measurements.

\section{Radio occultation missions}

On 15 July 2000 the German scientific satellite CHAMP (CHAllenging Minisatellite Payload) was launched from the Russian cosmodrome base Plesetzk to an initial altitude of $454 \mathrm{~km}$ (Wickert et al., 2004a). The radio occultation experiment was started on 11 February 2001. It was finished in beginning of October 2008. During the nearly eight years of RO measurements, CHAMP provided an almost continuous time series of about 200 limb soundings per day. Scientific objectives of the CHAMP mission also include the observation of the Earth's magnetic field as well as its gravity field. 

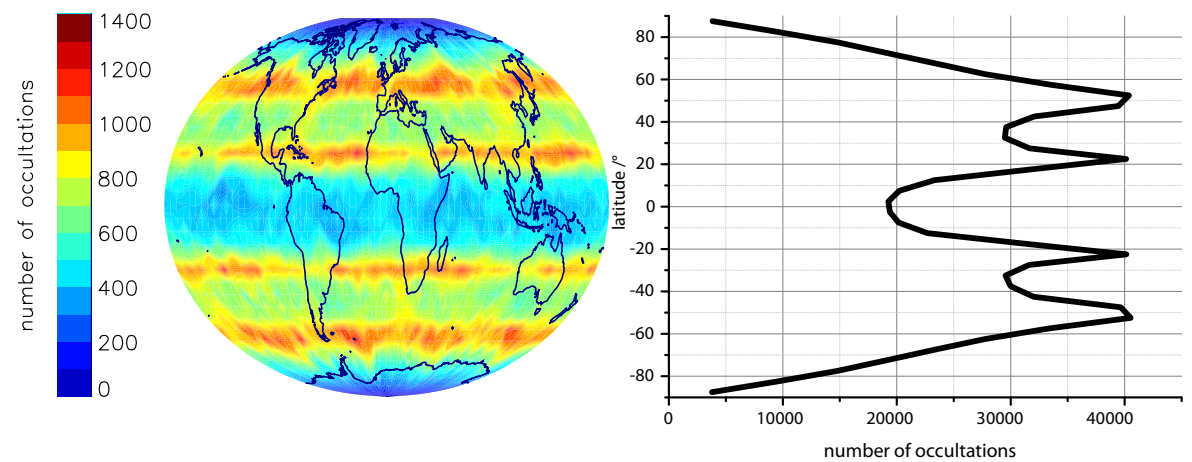

Fig. 3. Global distribution of radio occultation measurements performed by CHAMP, GRACE and COSMIC in 2008.

Important results of this mission are summarised by Reigber et al. $(2003,2005)$.

Two years later, on 17 March 2002, the joint U.S. American and German mission GRACE (GRAvity Recovery and Climate Experiment) was started. The GRACE mission consists of two identical satellites orbiting with a distance of about $220 \mathrm{~km}$ in an altitude of initially $500 \mathrm{~km}$. The major subjective of this mission is to monitor changes in the Earth's gravity field (Ward et al., 2004). The RO experiment has been started not until early 2006. Since then GRACE allocates about 150 data sets per day.

The joint US American and Taiwanese mission FORMOSAT-3/COSMIC (FORMOsa SATellite mission \#3/Constellation Observing System for Meteorology, Ionosphere and Climate) consists of six mini satellites. They were launched on 15 April 2006 to an initial parking position in $512 \mathrm{~km}$ altitude. The satellites reached their final orbit configuration about 17 months later flying now in an altitude of about $800 \mathrm{~km}$. The COSMIC mission is oriented to neutral atmospheric and ionospheric investigations (Rocken et al., 2000; Anthes et al., 2008).

An overview on the characteristics of the three missions is given in Table 1. All three missions allow investigations of the lower ionospheric E-region with $50 \mathrm{~Hz}$ sampling rate which corresponds to a height resolution of $\sim 50 \mathrm{~m}$.

\section{Global distribution of RO measurements}

In total 2478829 profiles between 2001 and 2008 are analysed. The allocation of performed measurements to each satellite mission is summarised in Table 2. In the years 2007 and 2008 the three satellite missions provided about $2500 \mathrm{RO}$ measurements per day on an average. Although COSMIC provides profiles only since summer 2006 its number exceeds by far the sum of measurements performed by CHAMP and GRACE. This is due to the usage of six satellites carrying a modified GPS receiver that allows tracking of both rising and setting occultations instead of only setting occulta-
Table 2. Total number of RO measurements between 2001 and 2008.

\begin{tabular}{llll}
\hline Satellite & $\begin{array}{l}\text { Total number } \\
\text { of RO }\end{array}$ & Mean daily RO & Detected $E_{S}$ \\
\hline CHAMP & 541527 & $\sim 200$ & 63618 \\
GRACE & 141987 & $\sim 150$ & 20068 \\
COSMIC & 1796315 & $\sim 2200$ & 285125 \\
Total & 2479829 & & 368811 \\
\hline
\end{tabular}

tions measured by GRACE and CHAMP. A unique feature is the almost continuous, nearly eight year long time series of CHAMP measurements that allows for initial trend analysis of atmospheric parameters.

One advantage of the RO technique is that the vertical profiles are spread all over the globe. Figure 3 shows the distribution of CHAMP, GRACE and COSMIC radio occultations during the year 2008. The number of profiles are summed up in a $5 \times 5$ degree latitude/longitude grid. On the right hand side the number of profiles is summed up over each $5^{\circ}$ latitude band. Obviously the profiles are not equally distributed. Four parallel bands of high profile counts appear spanning symmetrically around the globe at about $20^{\circ} \mathrm{N} / \mathrm{S}$ and $45^{\circ} \mathrm{N} / \mathrm{S}$. They are originating from the satellite geometry. RO measurements take place more frequently at locations where LEO satellites have convenient position to the GPS satellites. Although there are large variations of up to $50 \%$ in the number of measurements at each grid point, everywhere enough measurements are located to perform further analysis.

\section{Detection of sporadic $E$ layers from RO measurements}

For the detection of sporadic $E$ layers the Signal-to-Noise Ratio (SNR) is used. The SNR value is directly recorded by LEO satellites. In absence of ionospheric disturbances the 


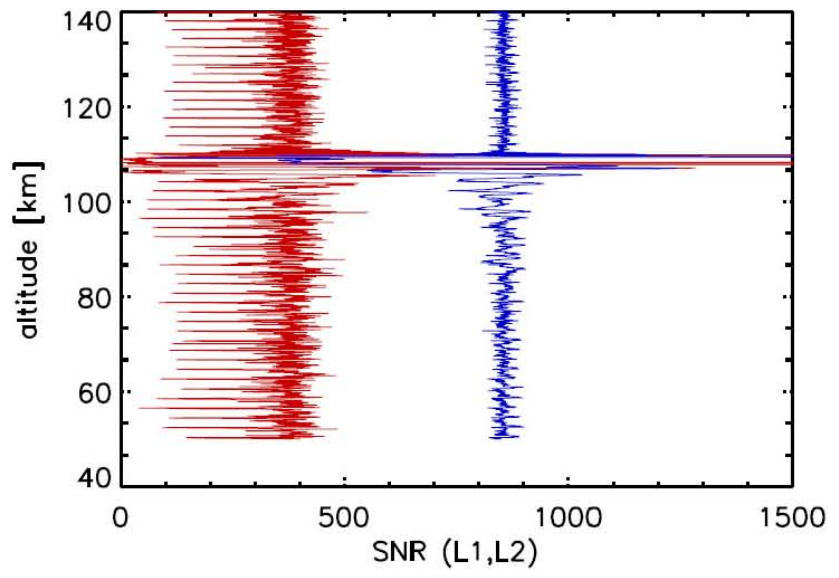

Fig. 4. A typical SNR profile for the GPS $L_{1}$ (blue) and $L_{2}$ (red) signal of a CHAMP occultation.

value is almost constant with height at altitudes above about $35 \mathrm{~km}$. Beneath, it decreases quickly due to absorption of signal power by atmospheric water vapour in the lower atmosphere. The SNR free-space value usually reach values between 250 and almost 1000 varying significantly from occultation to occultation. The free-space value depends on the viewing angle of the occulting GPS satellite with respect to the LEO antenna. A typical SNR profile is shown in Fig. 4 for the GPS $L_{1}$ (indicated in blue) and $L_{2}$ (red) signals. The $L_{2}$ signal is significantly weaker compared to the $L_{1}$ signal. This is due to the fact that the $L_{2}$ wave is encoded and has to be reconstructed. The reconstruction is only possible at expense of signal power. Therefore, the detection algorithm of sporadic $E$ layers from RO measurements makes only use of the stronger $L_{1}$ wave.

Strong and vertically small variations in the SNR in altitudes between 90 and $130 \mathrm{~km}$ are mainly caused by strong vertical gradients in electron density and therefore by sporadic $E$ layers. To extract the information from SNR profiles, an empirical detection algorithm similar to the one described by Wickert et al. (2004b); Wu (2006) is used. At first, the SNR profile is normalised to avoid errors induced from the different SNR free-space values. Afterwards the standard deviation is calculated from the normalised SNR in $2.5 \mathrm{~km}$ height intervals. If the standard deviation exceeds an empirically found threshold, the respective profile contains a distinct disturbance and it is associated to a sporadic $E$ layer. The altitude of the $E_{s}$ layer is allocated to the altitude of maximum deviation of the normalised profile from the free-space value. In case that the standard deviation reaches the boundary threshold in more than five height intervals the profile is rejected from further studies since disturbances over such large height ranges are usually not caused by sporadic $E$ layers.

Adv. Radio Sci., 8, 225-230, 2010
Detrimentally, the SNR profiles provide no information on the electron density of the layer. However, from the RO data also the geographic coordinates are known. So it is possible to get a 4-D picture of the number of detected sporadic $E$ layers in dependence on latitude, longitude, altitude and local time. This leads to the production of a sporadic $E$ climatology (Wu et al., 2005; Arras et al., 2008) or investigations of the sporadic $E$ formation process that is obviously dependent on the strength of Earth's magnetic field (Whitehead, 1961), meteor influx (Plane, 2003; Haldoupis et al., 2007) and highly correlated with vertical shears of the thermospheric zonal wind that is mainly produced by atmospheric tides. The dependence of $E_{s}$ occurrence on lower thermospheric winds is reflected in the local time distribution of sporadic $E$ layers. For example in the northern midlatitudes $E_{s}$ rates show a diurnal descending structure following the phases of the tidal zonal wind shear (Arras et al., 2009).

In Fig. 5 we present altitude-latitude dependent crosssections of relative sporadic $E$ occurrence rates including measurements performed during day and night time. Note that sporadic $E$ rates are given in $1 / 1000$, i.e. the number of occultations with a detected sporadic $E$ layer per 1000 occultations is given. Sporadic $E$ layers appear in the altitude range between 90 and $120 \mathrm{~km}$ with maximum between 95 and $115 \mathrm{~km}$. The sporadic $E$ latitude distribution shows maxima between $20^{\circ}$ and $50^{\circ}$ latitude of both hemispheres, with a clear seasonal cycle with maximum in summer and minimum in winter. Highest $E_{s}$ rates with values around $2 \%$ are observed during northern summer on the northern hemisphere. During equinox seasons the highest sporadic $E$ rates are concentrated to lower latitudes between $10^{\circ}$ and $30^{\circ}$ north or south, respectively. A well-defined gap along the equator is visible during all seasons in the altitude-latitude cross-sections, which is connected with the magnetic equator. The height-latitude structure of sporadic $E$ occurrence during 2008 is very similar to the one presented in Arras et al. (2008) for the autumn 2006-summer 2007 time interval. Differences are seen especially during spring; in 2008 the occurrence rates are substantially higher than during spring 2007, which indicates some interannual variability of $E_{s}$ frequency.

\section{Comparison of $E_{s}$ altitudes found from $\mathrm{RO}$ and ionosonde measurements}

Since the described empirical detection algorithm relies on a couple of assumptions a validation process is required to confirm the results. Sporadic $E$ altitudes are therefore compared with coinciding ground-based ionosonde measurements performed by the ionosonde located in Juliusruh, Germany $\left(54^{\circ} \mathrm{N}, 13^{\circ} \mathrm{E}\right)$. Ionosonde soundings give reliable measurements of electron density and altitude of $E_{s}$ layers. The altitudes are given in virtual heights, $h^{\prime} E_{s}$, representing the lower boundary of the layers. However, the virtual height does usually not equal the geometric one given 

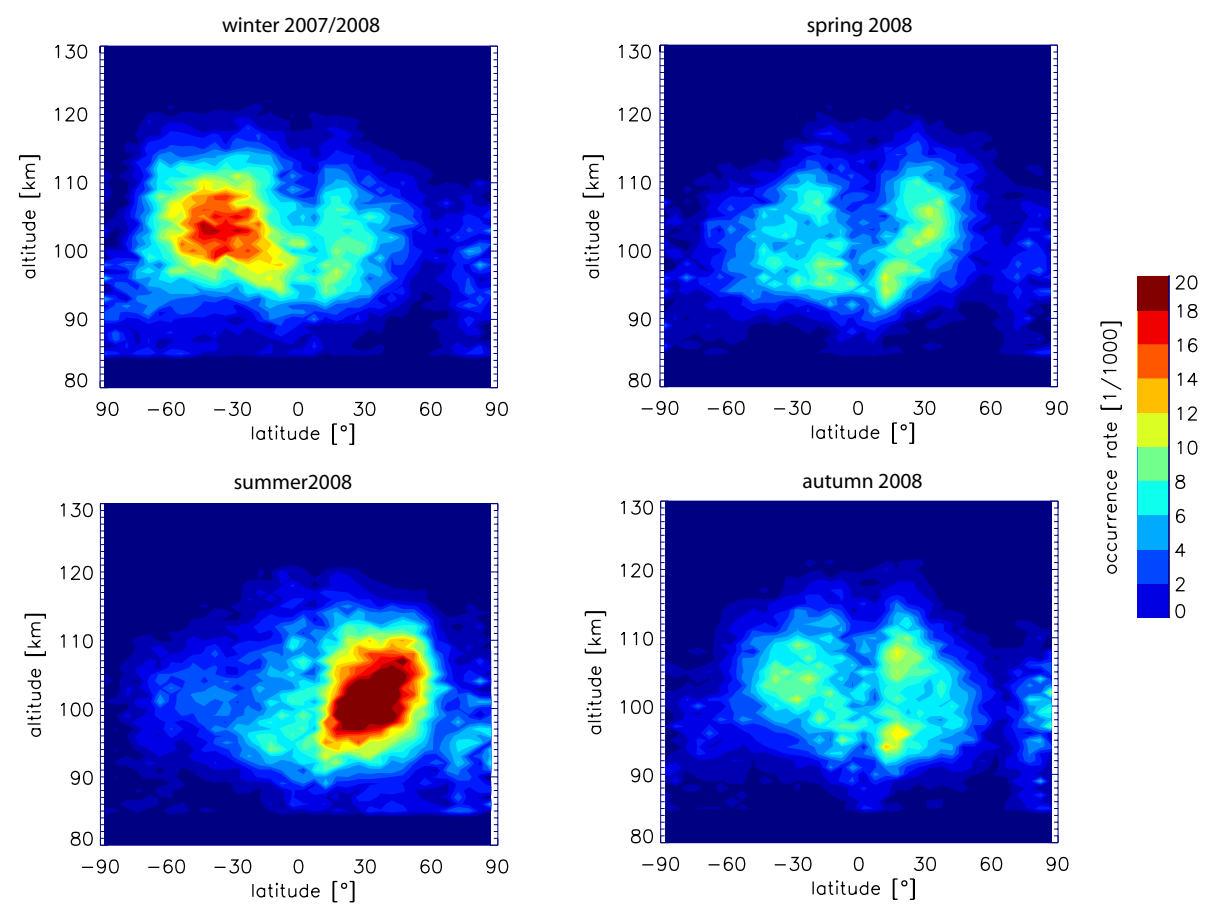

Fig. 5. Altitude-latitude cross-sections of sporadic $E$ occurrence rates in a $1 \mathrm{~km} \times 5^{\circ}$ resolution. Each plot contains measurements collected during three month: winter (December 2007, January and February 2008), spring (March, April, May 2008), summer (June, July, August 2008) and autumn (September, October, November 2008).

by RO profiles. The difference between virtual and geometric heights is governed by the amount of ionisation the ionosonde signal travels through. Thus, the signal is delayed and the result is an overestimation of the geometric height. To minimize this difference we concentrate only on measurements taken place in winter and during night, when the D-layer ionisation is generally low.

The comparison of geometric $E_{s}$ altitudes from COSMIC RO measurements with virtual ionosonde heights during the year 2007 is displayed in Fig. 6. Measurements from the COSMIC RO data set are only considered if they are not farther located from the Juliusruh ionosonde than $\pm 5^{\circ}$ both in east-west and north-south direction. A high correlation of about $90 \%$ is found between $E_{S}$ altitudes from RO and ionosonde recordings. A height offset of approximately $2.8 \mathrm{~km}$ is calculated from the regression analysis. Accordingly, RO measurements overestimate $E_{s}$ altitudes compared to ionosonde virtual heights by the given value for the night time. The difference results from the fact that ionosondes measure the height of the lower boundary of the layers, while RO usually senses the region of maximum SNR in the upper part of the $E_{s}$ layer.

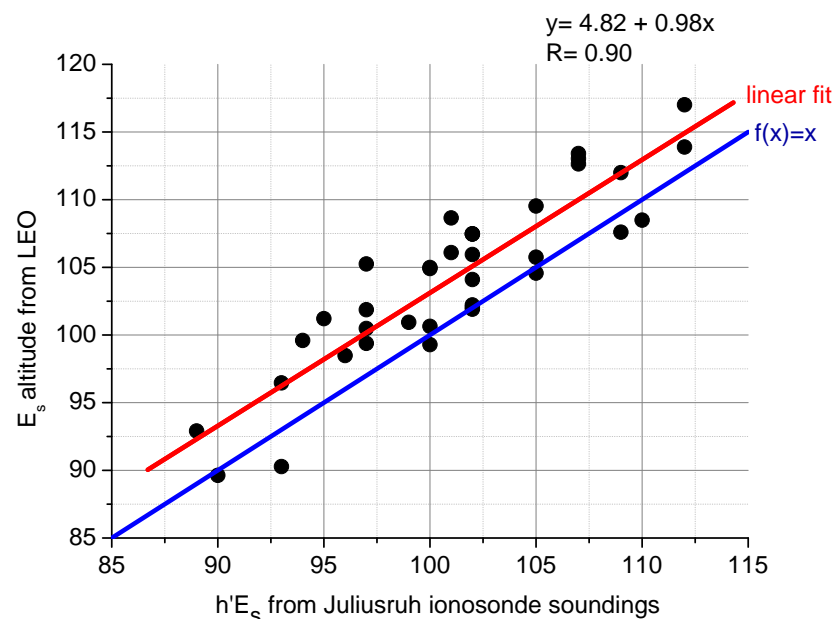

Fig. 6. Comparison of sporadic $E$ altitudes detected by ionosonde Juliusruh, Germany with coinciding $E_{S}$ altitudes from COSMIC RO measurements. 


\section{Conclusions}

CHAMP, GRACE and COSMIC radio occultation measurements provide an excellent data base for lower ionospheric observation on a global scale at a high spatial resolution. Sporadic $E$ signatures can be extracted from the directly measured SNR value of the GPS $\mathrm{L}_{1}$ signal. The algorithm allows only the estimation on $E_{S}$ altitudes but does not provide information on the layers electron density or its temporal behaviour. The comparison of sporadic $E$ altitudes with the ones from coinciding ionosonde measurements have shown that there is a strong correlation between the to methods. Consequently, the RO technique can be used as a method complementary to ground-based ionosondes to monitor sporadic $E$ layers in the lower ionosphere on a global scale.

Acknowledgements. The operational support of the CHAMP and GRACE missions by the German Aerospace Centre (DLR), the provision of FORMOSAT-3/COSMIC data by University Corporation of Atmospheric Research (UCAR) and the free provision of ionosonde data by the DIAS project page are gratefully acknowledged. This work is partly supported by the Deutsche Forschungsgemeinschaft (DFG) Priority Program CAWSES, SPP 1176. Topical Editor M. Förster thanks J. Bremer and an anonymous reviewer for their help in evaluating this paper.

\section{References}

Anthes, R. A., Bernhardt, P. A., Chen, Y., Cucurull, K., Dymond, K. F., Ector, S., Healy, S. B., Ho, S.-P., Hunt, D. C., Kuo, Y.-H., Liu, H., Manning, K., McCormick, C., Meehan, T. K., Randel, W. J., Rocken, C., Schreiner, W. S., Sokolovskiy, S. V., Syndergaard, S., Thompson, D. C., Trenberth, K. E., Wee, T.-K., Yen, N. L., and Zhang, Z.: THE COSMIC/FORMOSAT-3 MISSION: Early Results, B. Am. Meteorol. Soc., 89(3), 313-333, doi:10.1175/BAMS-89-3-313, 2008.

Arras, C., Wickert, J., Jacobi, C., Heise, S., Beyerle, G., and Schmidt, T.: A global climatology of ionospheric irregularities derived from GPS radio occultation, Geophys. Res. Lett., 35, L14809, doi:10.1029/2008GL034158, 2008.

Arras, C., Jacobi, C., and Wickert, J.: Semidiurnal tidal signature in sporadic $E$ occurrence rates derived from GPS radio occultation measurements at higher midlatitudes, Ann. Geophys., 27, 25552563, 2009,

http://www.ann-geophys.net/27/2555/2009/.
Hajj, G. A. and Romans, L. J.: Ionospheric electron density profiles obtained with the Global Positioning System: Results from the GPS/MET experiment, Radio Sci., 33, 175-190, 1998.

Haldoupis, C., Pancheva, D., Singer, W., Meek, C., and MacDougall, J.: An explanation for the seasonal dependence of midlatitude sporadic $E$ layers, J. Geophys. Res., 112, A06315, doi: 10.1029/2007JA012322, 2007.

Kursinski, E. R., Hajj, G., Hardy, K. R., Schofield, J. T., and Linfield, R.: Observing the Earth's atmosphere with radio occultation measurements using the Global Positioning System, J. Geophys. Res., 102, 23429-23465, 1997.

Plane, J. M. C.: Atmospheric Chemistry of Meteoric Metals, Chem. Rev., 103, 4963-4984, 2003.

Reigber, C., Lühr, H., and Schwintzer, P., eds.: First CHAMP Mission Results for Gravity, Magnetics and Atmospheric Studies, Springer-Verlag Berlin, Heidelberg, New York, 2003.

Reigber, C., Lühr, H., Schwintzer, P., and Wickert, J.: Earth Observation with CHAMP Results from Three Years in Orbit, Springer Berlin, Heidelberg, New York, 2005.

Rocken, C., Anthes, R., Exner, M., Hunt, D., Sokolovskiy, S., Ware, R., Gorbunov, M., Schreiner, W., Feng, D., B., H., Kuo, Y.-H., and Zou, X.: Analysis and validation of GPS/MET data in the neutral atmosphere, J. Geophys. Res., 102, 29849-29866, 1997.

Rocken, C., Kuo, Y.-H., Schreiner, W. S., Hunt, D., Sokolovskiy, S., and McCormick, C.: COSMIC System Description, Terr. Atmos. and Oceanic Sci., 11(1), 21-52, 2000.

Ward, A., Bagui, M., and Reigber, C., eds.: GRACE Gravity Recovery and Climate Experiment, Goddard Space Flight Center, Greenbelt, Maryland, 2004.

Whitehead, J.: The formation of the sporadic-E layer in the temperate zones, J. Atmos. Terr. Phys., 20, 49-58, 1961.

Wickert, J., Pavelyev, A., Liou, Y., Schmidt, T., Reigber, C., Igarashi, K., Pavelyev, A., and Matyugov, S.: Amplitude variations in GPS signals as a possible indicator of ionospheric structures, Geophys. Res. Lett., 31, L24801, doi:10.1029/ 2004GL02607, 2004a.

Wickert, J., Schmidt, T., Beyerle, G., König, R., Reigber, C., and Jakowski, N.: The Radio Occultation Experiment aboard CHAMP: Operational Data Analysis and Validation of Vertical Atmospheric Profiles, J. Meteorol. Soc. Jpn., 82, 381-395, 2004b.

Wu, D. L.: Small-scale fluctuations and scintillations in highresolution GPS/CHAMP SNR and phase data, J. Atmos. Sol. Terr. Phys., 68, 999-1017, 2006.

Wu, D. L., Ao, C. O., Hajj, G. A., de la Torre Juarez, M., and Mannucci, A. J.: Sporadic E morphology from GPS-CHAMP radio occultation, J. Geophys. Res., 110, A01306, doi:10.1029/ 2004JA010701, 2005. 